DOI: $10.20472 /$ TEC.2018.006.002

\author{
KELUM GAMAGE \\ University of Glasgow, United Kingdom
}

SAJJAD HUSSAIN

University of Glasgow, United Kingdom

QAMMER H. ABBASI

University of Glasgow, United Kingdom

\title{
FINAL YEAR PROJECT ALLOCATIONS FOR UNDERGRADUATE ENGINEERING STUDENTS IN TNE PROGRAMS
}

\begin{abstract}
:
Final year project allocations become a challenging task, particularly, in the case of a large number of undergraduate students enthusiast to get a project of their interest and/or to work with a supervisor of their choice. The problem is challenging as the interest of all the students should be matched while keeping the staff workload in balance. It becomes a matching problem with the constraints of staff workload, student preferences, and staff skillset. Particularly, in the Transnational Education (TNE) programs, the physical availability (or lack of it) of the staff plays an important part in the student project selections which gives an additional challenge to the allocation problem. Authors provide a review of different final year project allocation methods currently in practice and discuss their strengths and weaknesses with respect to the constraints highlighted. Authors finally conclude by discussing an algorithm which can work effectively and efficiently in the context of project allocations for TNE progragrams.
\end{abstract}

\section{Keywords:}

Transnational Education (TNE), Final year projects, Matching problem, project allocations, staff workload 


\section{Introduction}

Final year undergraduate projects are generally a key part of any science and engineering degree program. It can be considered as the most substantial project undertaken by an undergraduate during their degree, and largely it provides the first opportunity for students to work independently on a project for a year. Throughout the project, students are required to apply the scientific knowledge they gained during their studies as well as learn new science. Student learning outcomes from final year projects can be divided primarily into two categories: knowledge of science and general skills (Ryder, 2004). For example, knowledge of science refers to the design of an experimental or computational study, problem-solving skills whereas time management, creative thinking and communicating results can be considered as general skills. Final year projects are generally resource intensive, where the student needs strong academic supervision throughout the project duration. Achieving a passing grade for the final year project is critical, for example, if a student is unsuccessful to attain the passing grade he or she may not be even awarded an accredited degree.

Allocation of projects to students, assessment procedures, access to resources, support and supervision, and general management of projects can be considered as key influential parameters which govern students' learning experiences during the final year project (Teo and Ho, 1998). For example, if students were allocated to projects or supervisors arbitrarily, without considering students' preferences or without considering project supervisors' research interest, generally resulting in a poor or unsatisfactory relationship between the student and the supervisor (Salami and Mamman, 2016). It ultimately affects negatively to the students' learning experience during the final year. Project allocation is a resource allocation problem with certain constraints, where to enhance the student learning experience and satisfaction, it is also essential to consider students' preferences for projects.

University academics, particularly in the field of science and engineering, have shown great interest regarding the practices currently used to allocate final year undergraduate students to projects (Harlan et al., 2005, I'Anson and Smith, 2004, Salami and Mamman, 2016). With the prospect of a Teaching Excellence Framework (TEF) on the horizon for universities in the United Kingdom, actions to improve the National Student Survey (NSS) scores have become a vital exercise for many academics. NSS measures student satisfaction from a range of aspects where it is mainly aimed at final year undergraduate students. Final year project is a vital element of the final year undergraduate program and it can significantly impact the NSS scores. Consequently, allocating final year undergraduates to the correct projects is essential to improve the students learning experience, student engagement and finally to enhance student satisfaction.

\section{Project Allocation Methods}

There are several project allocation methods employed by various engineering universities around the globe. Each method has some pros as well as cons. However, specific to the TNE programs, there are additional challenges. Authors shall present those challenges and then evaluate different allocation methods currently in practice. 


\subsection{Challenges in TNE project allocations}

Allocation of final year undergraduates to projects is also a key challenge for TNE programs. The global growth of transnational education is rapidly increasing and becoming an integral part of the internationalization strategy of most universities. TNE is generally challenging for science and engineering programs, particularly to sustain high standards with all the other constraints and to meet the requirements of accreditation organizations (Miliszewska et al., 2003). This becomes substantial when students enter into their final year of studies. For example, allocation of final year projects to students should be conducted considering all the constraints associated with TNE. Simultaneously, it is critical to ensure that student learning and engagement during the project sustain at the highest level, and should demonstrate the effectiveness of the selected project allocation mechanism.

With the increasing number of constraints, universities have to rethink about the techniques used to allocate final year projects to students while further improving student learning and student satisfaction. This becomes a significant challenge with increasing number of students in science and engineering programs including a rapid increase in student numbers in TNE programs. Simultaneously, universities are subjected to increased scrutiny, to maintain high standards, from accreditation bodies as well as through potential TEF. There are numerous final year project allocation techniques published in the literature, where the primary objective of this paper is to review such techniques with the focus of identifying the effectiveness of those techniques with respect to the challenges highlighted above.

For instance, in some TNE programs the staff working model is fly-in-fly-out (FIFO) where some of the staff members only fly for a particular number of days or weeks in a semester to teach and supervise the students in the non-local campus. While, some of the staff members are permanently placed in such locations and thus there arises a mismatch in the physical availability of the staff.

Therefore, interactions between the supervisors and the students may be limited thus arises the need of local staff to play an active role as second supervisors. In case the local staff takes the responsibility of first supervision, the load on the visiting faculty is reduced to provide a better supervision experience to the students. As a result, students experience less disadvantages of remote supervision as the visiting staff are able to dedicate more time to a reduced number of supervised students. When the local staff takes the responsibility of second supervision, the absence of visiting staff is partially compensated by the on-campus staff.

Now, with the participation of local staff in the project supervision brings an additional constraint while the projects are allocated to the students. This additional constraint has to be taken into consideration while the projects are allocated. One of the solutions is to fix a ratio of the projects that the students could choose from local supervisors to the FIFO supervisors. This should normally result in a trade-off between quality of supervision, staff workload and student satisfaction. However, the complexity of the problem increases as the balance between the number of proposed projects and/or available supervisors from both sides may not be appropriate.

Further, there is a possibility that students may have a tendency to prefer the staff from a specific group of supervisors (local or non-local) while making their selections due to several reasons. For 
instance, the global visibility of the foreign staff, on-campus availability of the staff or presence (or absence) of the drive to communicate in non-native language etc. The allocation algorithm then needs not only to keep the student preferences into account but also keep the pre-agreed balance between the staff supervisions from both sides. There should be solutions which could take care of student preferences while balancing the staff load, not only between the two sides but also among the staff members of each sides. This makes the problem more challenging.

\subsection{Evaluation of Project Allocation Methods}

Undergraduate final year projects offer opportunities for students to undertake independent project work and to develop subject-specific as well as generic skills. It also provides an opportunity for staff to work closely with the student and, strengthen individual student's skills, which are not visible from a standard course assessment. However, the success of achieving some of these underlined objectives also depends on the project allocation scheme used at the beginning. Various types of project allocation techniques are used in engineering and science streams:

i) Project selection by students based on project titles provided by staff

ii) Project allocation based on preferences of both (or negotiation between) students and supervisors

\section{iii) Project based on student's own proposal}

Each allocation technique has potential strengths and weaknesses, where students' choice of project is influenced by their desire to work with a particular academic staff member or desire for a particular project work (Harlan et al., 2005).

For example, in case the students are to manually choose the project, provided by staff, there will be a competition among students for some specific projects and/or supervisors. This may provide some of the students as well as staff to work on their preferred topic with their preferred students, but there is a high probability of students being not able to find their best match in terms of projects and supervisors. However, if the students and staff are allowed to negotiate, it may not only prolong the allocation process and thus leaving less time for actual project work, but also, it may end up overloading some of the staff members as compared to the others.

If the students are asked to provide their own proposals, this might result in mismatch with the supervisor skills and ability to supervise a project out of their research domain. Also, the quality of the proposals will be subject to the students' quality and in most of the cases this may result in overall quality degradation for the process.

Project allocation is a resource allocation problem where the key constraints are to load the staff appropriately while matching projects to students' demands. Therefore, it becomes a matching problem and if solved mathematically under given constraints, the optimal solutions can be achieved. The problem with student preferences over projects is discussed in David and Gregg, 2008 and the work is further improved in Frances and David, 2018. The authors used these algorithms for the final year project allocations for a TNE program with 188 students and 16 supervisors from the non-local side while 88 supervisors from the local institute. There was a limit of supervision of a maximum of 8 project supervisions per non-local staff while an upper cap of 4 supervisions was applied for the local staff. The students were asked to rank their preferences 
according to their interest from the projects, proposed from both sides. However, due to the unbalance between the numbers of supervisors, the additional constraint was to make three preferences from non-local staff while 6 preferences from local staff, thus each student had to pick 9 projects in all. The objective of the allocation algorithm was to assign the top ranked projects to a maximum number of students.

In Fig. 1 authors present some of the initial results for the allocations. As it can be seen that most of the students got their top ranked preferences as their allocated project. A very small number of the student portion got their project ranked below 3 in their preference list. However, there were 4 students whose none of the preference could be matched to their allocation.

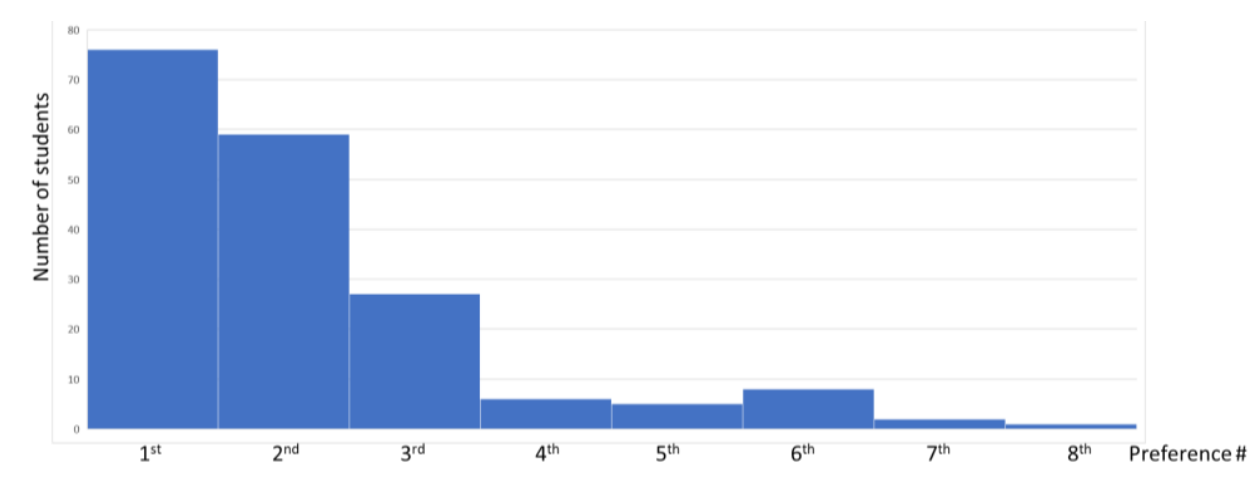

Fig. 1: Matching of the student preferences to their project allocations

\section{Discussion and Conclusion}

Final year project allocations can be challenging task especially in the context of TNE programs which introduce additional challenges. The allocations, if done manually, can be time consuming and also can cause student complaints about the fairness of the process. However, if the allocations are automated through an optimisation algorithm which takes some constraints and works on some objective function to produce the optimal outputs, the project allocations not only become efficient but are less subjected to student complaints. There are algorithms which can match student allocations to their preferences. However, there are scenarios where the algorithm may not find the complete matching. In such scenarios, manual means can be used for a small number of students whose allocations could not be matched to their preferences. One way could be extending the scope of the top ranked projects for the non-allocated students and assigning them an approximate version of their preference.

\section{Acknowledgment}

The authors would like to acknowledge Prof. David Manlove and Frances Cooper for their help of sorting raw data through their algorithm to materialise the project allocations presented in Fig. 1. 


\section{References}

David F. Manlove, Gregg O'Malley, Student-Project Allocation with preferences over Projects, Journal of Discrete Algorithms, Volume 6, Issue 4, 2008.

Frances, C., David, .F., Manlove. A 3/2-approximation algorithm for the Student-Project Allocation problem. In Proceedings of SEA 2018, vol. 103 of LIPIcs, pg 8:1-8:13.

Harland, J., Pitt, S., Saunders, V., Factors affecting student choice of the undergraduate research project: staff and student perceptions, Bioscience Education, vol. 5 (2005) pp. 1-19.

I'Anson, R.A., Smith, K.A., Undergraduate Research Projects, and Dissertations: issues of topic selection, access and data collection amongst tourism management students, Journal of Hospitality, Leisure, Sport and Tourism Education, vol. 3 (2004) pp. 19-32.

Miliszewska, I., Horwood, J., and McGill, A., Transnational Education through Engagement: Students' Perspective, Proc. of Informing Science and IT Education Conference, Pori, Finland, (2003) pp. 165173.

Ryder, J., What can students learn from final year research projects? Bioscience Education, vol. 4 (2004) pp. 1-8.

Salami, H.O., Mamman, E.Y., A Genetic Algorithm for Allocating Project Supervisors to Students, International Journal of Intelligent Systems and Applications, vol. 10 (2016) pp. 51-59.

Teo, C.Y. and Ho, D.J., A Systematic Approach to the Implementation of Final Year Project in an Electrical Engineering Undergraduate Course, IEEE Transactions on Education, vol. 41 (1998) pp. 25-30. 